\title{
Bachelor of Pharmacy Programs in United Arab Emirates
}

\author{
Akram Ashames \\ Department of Pharmaceutical Sciences, College of Pharmacy and Health Sciences, Ajman University, United Arab Emirates
}

Copyright $\subseteq 2019$ by authors, all rights reserved. Authors agree that this article remains permanently open access under the terms of the Creative Commons Attribution License 4.0 International License

\begin{abstract}
The United Arab Emirates (UAE) pharmacy education has undergone significant reform in recent years to introduce more clinical and social pharmacy courses to replace many traditional pharmaceutical sciences courses that were typically dominate pharmacy curricula. The aim of this work was to carry out a comprehensive comparative analysis on all Bachelor of Pharmacy (BPharm) programs in the UAE and to describe the developments of BPharm curricula offered by UAE colleges of pharmacy after increasing the number of credit hours allocated for clinical and social pharmacy courses. BPharm curricula offered by all pharmacy colleges in the UAE were retrieved from their official websites. A comparative study on different curricula was carried out to investigate the structure of BPharm curricula after incorporating more patient-centered courses. Clinical and social pharmacy courses represent between $22 \%$ and $51 \%$ of the total BPharm credit hours. Non-clinical/social courses are no longer representing the majority of BPharm courses. PharmD degree program is offered by only one university. The course credit hour distribution of different BPharm programs is varied from one program to another. More clinical and social pharmacy courses are increasingly replacing the traditional pharmaceutical sciences subjects such as pharmaceutics, chemistry, biomedical, and basic sciences.
\end{abstract}

Keywords Pharmacy Education, BPharm, PharmD, Clinical Pharmacy, Social Pharmacy, CAA, UAE, ACPE

\section{Introduction}

United Arab Emirates (UAE) is an emerged federation of seven Emirates with a population amounted to 9.3 million in 2017 (1). The UAE is a role model of a multinational country where expatriates from more than 200 nationalities represent more than two-thirds of the population $(1,2)$

In less than half a century, the UAE has emerged as one of the global nations with top education system. The country has established a first-rate quality higher education system, and has witnessed a rise in establishing public and private higher instructional institutions.

Pharmacy is one of the most growing health sciences educational fields with nine pharmacy colleges distributed in almost all the Emirates of the country. In recent years, pharmacy education in UAE has progressed and many changes have been made to pharmacy undergraduate curricula to replace traditional courses with patient-centered pharmacy courses related to clinical and social pharmacy. This is in trend with the global changes in the pharmacy profession from product-oriented to a patient-centered (3).

There are handful publications that have described the pharmacy education in UAE and its status (4-9). However, up to the knowledge of the author no published study has been identified in literature that performed a comparative analysis of different Bachelor of Pharmacy (BPharm) programs offered by UAE universities. Thus, the aim of this work was to carry out a comprehensive analysis on all BPharm programs in the UAE and to describe the developments of BPharm curricula offered by UAE colleges.

\section{Background}

Around $91 \%$ of higher education institutions in UAE are private establishments, and $9 \%$ of universities are governmental where $30 \%$ of them are located in the capital city of Abu Dhabi (Table 1) (10).

In medical sciences, including pharmacy, UAE students represent only $12 \%$ of the total students registered in private higher education institutions in 2016-2017 as shown in Table 2 from official data (10). More than $51 \%$ of students are from Arab countries such as Syria, Iraq, Saudi Arabia, Egypt, Palestine, Jordan, and Yemen. On the other hand, around $89 \%(n=175)$ of medical science students registered in governmental higher education institutions in 2016-2017 are UAE citizens, compared to $11 \%(n=19)$ 
expats.

Pharmacy education in UAE dates back to 1990s when two colleges of pharmacy were founded, which are Dubai Pharmacy College that is exclusively for female students and College of Pharmacy and Health Sciences at Ajman University, for both genders, in 1992 and 1996, respectively, to offer BPharm programs (7). Years later, more pharmacy colleges were established in Emirates of Sharjah, Ajman, Abu Dhabi, and Ras Al Khaimah. Recently, a new BPharm program has been granted an initial accreditation and it will be launched latter in 2019 (7). There are nine pharmacy colleges/departments (Table 3), eight of them offer BPharm programs and one offers Doctor of Pharmacy (PharmD).

Table 1. Higher education institutions by Emirate and sector in 2016-2017 (4)

\begin{tabular}{|c|c|c|c|c|c|c|c|c|}
\hline \multirow{2}{*}{ Emirate } & \multicolumn{5}{|c|}{ Private } & \multicolumn{3}{c|}{ Government } \\
\cline { 2 - 9 } & University & College & Institute & Total & University & College & Total & \\
\hline Abu Dhabi & 7 & 13 & 9 & 29 & 2 & 1 & 3 & 32 \\
\hline Dubai & 13 & 18 & 3 & 34 & 1 & 1 & 2 & 36 \\
\hline Sharjah & 4 & 2 & 1 & 7 & 0 & 1 & 1 & 8 \\
\hline Ajman & 2 & 2 & 0 & 4 & 0 & 0 & 0 & 4 \\
\hline Umm Al-Quwain & 0 & 1 & 0 & 1 & 0 & 0 & 0 & 1 \\
\hline RAK & 2 & 0 & 0 & 2 & 0 & 1 & 1 & 3 \\
\hline Fujairah & 1 & 1 & 0 & 2 & 0 & 1 & 1 & 3 \\
\hline Grand Total & 29 & 37 & 13 & 79 & 3 & 5 & 8 & 87 \\
\hline
\end{tabular}

Table 2. Distribution of medical sciences students in private institutions by nationality in 2016-2017 (4)

\begin{tabular}{|c|c|c|c|c|c|c|c|}
\hline & \multicolumn{2}{|c|}{ GCC countries } & \multicolumn{2}{c|}{ Other countries } & \multicolumn{3}{c|}{ Total } \\
\hline Gender & UAE & GCC Countries & Arab Countries & Other & GCC countries & Other countries & Total \\
\hline Male & 88 & 99 & 999 & 325 & 187 & 1,324 & 1,511 \\
\hline Female & 481 & 385 & 1,400 & 886 & 866 & 2,286 & 3,152 \\
\hline Total & 569 & 484 & 2,399 & 1,211 & 1,053 & 3,610 & 4,663 \\
\hline
\end{tabular}

Table 3. List of Pharmacy Colleges/Departments in UAE offering undergraduate Pharmacy programs

\begin{tabular}{|c|c|c|c|c|c|c|}
\hline Institute & $\begin{array}{l}\text { Emirate, main } \\
\text { campus }\end{array}$ & $\begin{array}{c}\text { Establishing } \\
\text { year }\end{array}$ & $\begin{array}{l}\text { Undergraduate } \\
\text { pharmacy program }\end{array}$ & $\begin{array}{l}\text { Program } \\
\text { length } \\
\text { (Years) }\end{array}$ & Student gender & Sector \\
\hline DPC & Dubai & 1992 & BPharm & 5 & Female & Private \\
\hline $\mathrm{AU}$ & Ajman & 1996 & BPharm & 4 & Both & Private \\
\hline GMU & Ajman & 1998 & PharmD & 5 & Both & Private \\
\hline HCT & Dubai & 2003 & BPharm & 5 & Female, Citizens & Public \\
\hline UoS & Sharjah & 2005 & BPharm & 5 & Both & Private \\
\hline AAU & $\begin{array}{c}\text { Abu Dhabi, Al } \\
\text { Ain }\end{array}$ & 2006 & BPharm & 4.5 & Both & Private \\
\hline RAK & Ras Al Khaimah & 2007 & BPharm & 4 & Both & Private \\
\hline FCHS & Abu Dhabi & 2012 & BPharm & 5 & Both & Private \\
\hline CUCA & Ajman & 2019 & BPharm & 4 & Both & Private \\
\hline
\end{tabular}

DPC: Dubai Pharmacy College

AU: Ajman University

GMU: Gulf Medical University

HCT: High Colleges of Technology

UoS: University of Sharjah

AAU: Al Ain University of Sciences and Technology

RAK: Ras Al Khaimah (RAK) Medical \& Health Sciences University

FCHS: Fatima College of Health Sciences

CUCA: City University College of Ajman 
Two colleges are single-sex schools (for female students only), while the rest 7 are coeducational for both genders either integrated or segregated. In coeducational programs, female students typically represent about $70-80 \%$ of the total number of students. Students from all nationalities are allowed to pursue their pharmacy studies in almost all pharmacy colleges in UAE, except Dubai Women College (DWC), which is only for UAE citizens. Colleges are located in six Emirates, three in Ajman, two in Abu Dhabi, two in Dubai, one in Sharjah, one in Ras Al Khaimah, and one branch for Ajman University in Fujairah.

\section{Local and International Accreditation}

The Commission for Academic Accreditation (CAA), Ministry of Education, which is the local accreditation body of higher education programs in UAE, accredits all BPharm programs in UAE and the accreditation is renewable every five years (11). To date, only two BPharm programs offered by AAU and AU are internationally certified by the US based Accreditation Council for Pharmacy Education (ACPE) (12). No programs are currently accredited by other international accreditation bodies such as Canadian Council for Accreditation of Pharmacy Programs (CCAPP), the German Accreditation Agency in Health and Social Sciences (AHPGS), and the Australian Pharmacy Council (APC) (7).

\section{Pharmacy Enrollment Ceiling}

Approximately 800 new students enter to the colleges of pharmacy every year to pursue their pharmacy studies. CAA determines the number of admitted new students in BPharm programs for each college. The ceiling ranges from 50 to 150 students per college per year.

\section{Teaching and Assessment Methods}

English is the language of instruction in all pharmacy colleges. The teaching methods in almost all pharmacy colleges are didactic lecturing that combines problem-based learning (PBL) and outcome-based education (OBE) methods. Pharmacy colleges are also equipped with teaching laboratories to perform experimental sessions. Experiments cover pharmaceutics, chemistry, pharmacology, and biomedical areas. Clinical courses involve student role-playing a pharmacist using virtual pharmacies and experiential placements. Common assessment tools include exams, quizzes, case studies, and assignments. Recently, the colleges of pharmacy of Ajman University, University of Sharjah, and Al Ain University of
Science and Technology have started implementing objective structured clinical examination (OSCE) as assessment tool for their students.

\section{BPharm Program Development}

Most of BPharm programs in UAE have recently undergone noticeable developments to accommodate recent changes in the field of pharmacy to incorporate more clinical and social pharmacy courses. This has led to a drastic decrease in the number of credit hours historically allocated to common pharmacy areas such as pharmaceutical chemistry, pharmacognosy, and pharmaceutics. For instance, the ACPE certified BPharm program offered by Ajman University has been totally updated in 2019 (Figure 1). The percentage of credit hours devoted to clinical/social courses and trainings have been almost doubled from $17 \%$ to $32 \%$. This notable increase resulted in a significant cut in chemistry, pharmacognosy, and pharmaceutics credit hours. Chemistry-related credit hours were decreased from $18 \%$ to $12 \%$, whereas pharmaceutics courses were representing $21 \%$ of the previous BPharm curriculum credit hours are now account for $13 \%$ of new curriculum credit hours. Pharmacognosy-related courses were also reduced from $5 \%$ to $2 \%$, while biomedical courses were negligibly decreased from $19 \%$ to $18 \%$. However, general university requirement courses were increased from $16 \%$ to $19 \%$. It is worth mentioning that the total program credit hours were increased from 150 into 160 hours.

\section{BPharm Program Credit Hours}

The total credit hours of BPharm programs ranges from 132 to 170 hours (Figure 2). Dubai Women College (DWC) of High Colleges of Technology (HCT), Fatima College of Health Sciences (FCHS) of the Institute of Applied Technology (IAT), and RAK College of Pharmaceutical Sciences have the lowest number of BPharm program credit hours with 132, 140, and 145 hours, respectively. On the other hand, BPharm programs offered by University of Sharjah and Dubai Pharmacy College have the highest number of total credit hours with 170 and 168 hours, respectively. Ajman University (AU) and $\mathrm{Al}$ Ain University of Sciences and Technology BPharm (AAU) programs have the same number of credit hours with 160 hours each (13-19). To date, there are no official regulations that determine the minimum total credit hours for BPharm programs. It would be crucial that CAA set a threshold for minimum credit hours for BPharm programs in UAE that meets the 150 credit hours recommended by Scientific Society of Faculties of Pharmacy in the Arab World. 


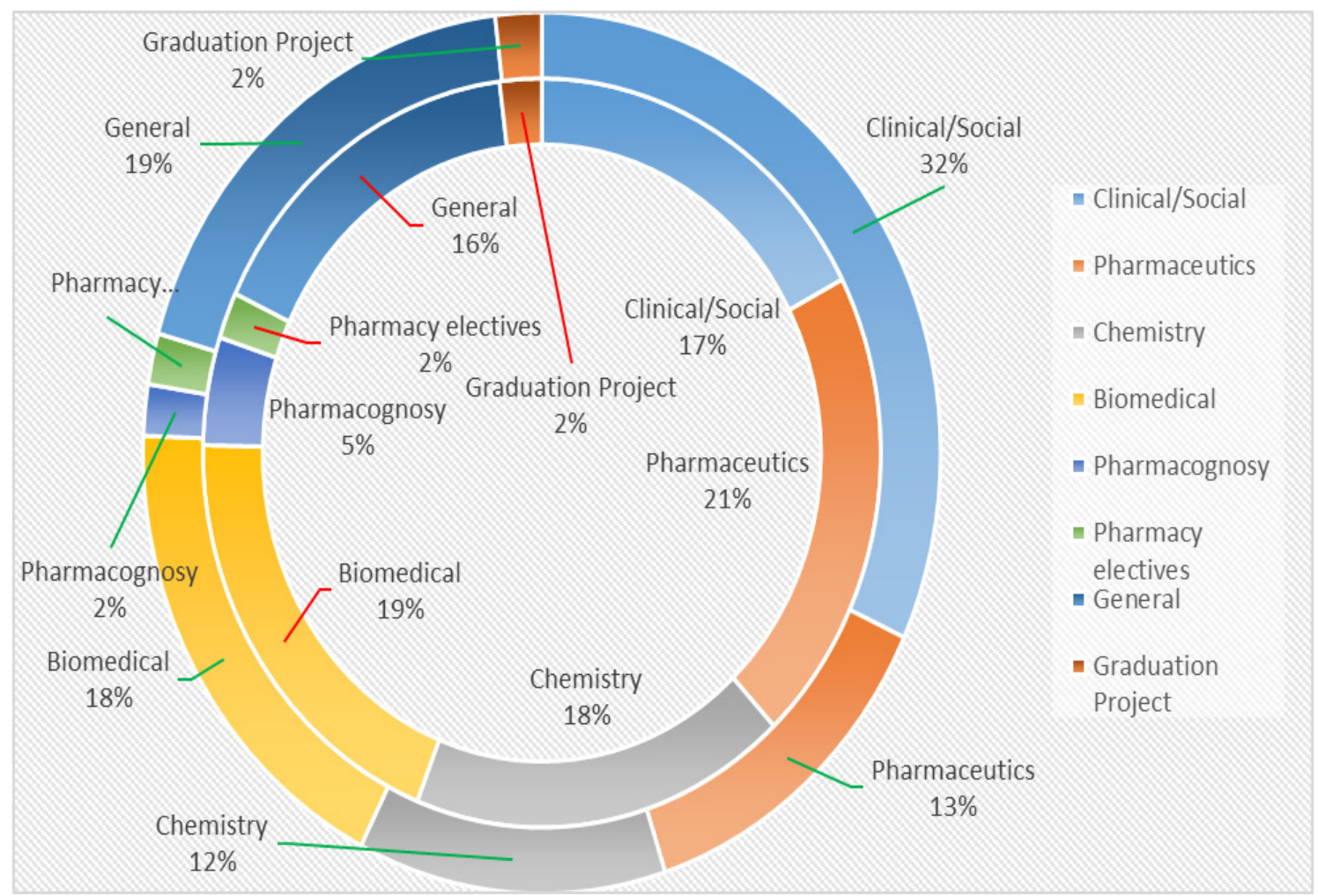

Figure 1. Credit hour distribution of old (inner circle, in red) and new (outer circle, in green) BPharm curricula offered by Ajman University

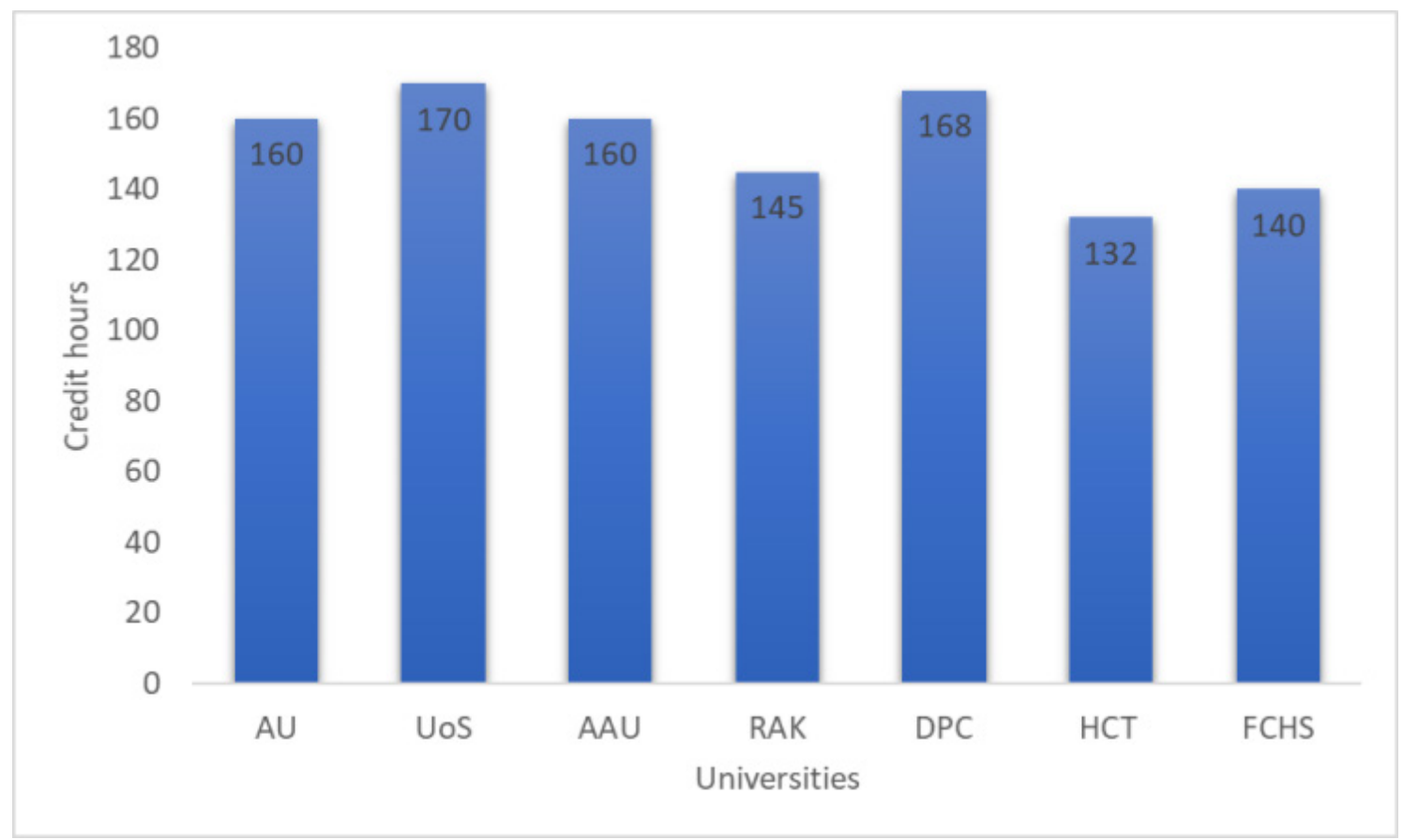

Figure 2. Total BPharm credit hours in different Pharmacy Colleges in UAE 


\section{Credit Hour Distribution}

The distribution of credit hours of different BPharm programs offered by UAE universities is shown in Table 4 and Figures 3 through 9. It is obvious that the course distribution of main pharmacy areas is varied from one college to another. Furthermore, the number of credit hours allocated for general university courses are enormously different form one program to another where it ranges from $0.0 \%$ credit hours in FCHS program to $29.5 \%$ (39 hours) of the BPharm program offered by HCT.

Table 4. Credit hour distribution of BPharm programs offered by UAE universities

\begin{tabular}{|c|c|c|c|c|c|c|c|}
\hline Course & $\begin{array}{c}\mathrm{AU} \\
\mathrm{n}(\%)\end{array}$ & $\begin{array}{c}\text { UoS } \\
\mathrm{n}(\%)\end{array}$ & $\begin{array}{c}\text { AAU } \\
\mathrm{n}(\%)\end{array}$ & $\begin{array}{c}\text { DPC } \\
\mathrm{n}(\%)\end{array}$ & $\begin{array}{c}\text { RAK } \\
\mathrm{n}(\%)\end{array}$ & $\begin{array}{c}\text { HCT, DWC } \\
\mathrm{n}(\%)\end{array}$ & $\begin{array}{c}\text { FCHS } \\
\mathrm{n}(\%)\end{array}$ \\
\hline Total Credit Hours & 160 & 170 & 160 & 168 & 145 & 132 & 140 \\
\hline Clinical/Social Pharmacy & $51(31.9 \%)$ & $43(25.3 \%)$ & $57(35.6 \%)$ & $54(32.1 \%)$ & $32(22.1 \%)$ & $42(31.8 \%)$ & $72(51.4 \%)$ \\
\hline Pharmaceutics & $21(13.1 \%)$ & $21(12.4 \%)$ & $19(11.9 \%)$ & $26(15.5 \%)$ & $34(23.4 \%)$ & $15(11.4 \%)$ & $21(15.0 \%)$ \\
\hline Chemistry & $20(12.5 \%)$ & $25(14.7 \%)$ & $18(11.2 \%)$ & $25(14.9 \%)$ & $29(20.0 \%)$ & $15(11.4 \%)$ & $15(10.7 \%)$ \\
\hline Biomedical $*$ & $29(18.1 \%)$ & $37(21.8 \%)$ & $22(13.8 \%)$ & $25(14.9 \%)$ & $25(17.2 \%)$ & $12(9.1 \%)$ & $32(22.9 \%)$ \\
\hline Pharmacognosy & $3(1.9 \%)$ & $4(2.3 \%)$ & $5(3.1 \%)$ & $11(6.5 \%)$ & $2(1.4 \%)$ & $3(2.3 \%)$ & $0(0.0 \%)$ \\
\hline Pharmacy Electives & $3(1.9 \%)$ & $3(1.8 \%)$ & $0(0.0 \%)$ & $6(3.6 \%)$ & $0(0.0 \%)$ & $0(0.0 \%)$ & $0(0.0 \%)$ \\
\hline General & $30(18.7 \%)$ & $33(19.4 \%)$ & $39(24.4 \%)$ & $15(8.9 \%)$ & $23(15.9 \%)$ & $39(29.5 \%)$ & $0(0.0 \%)$ \\
\hline Graduation Project & $3(1.9 \%)$ & $4(2.3 \%)$ & $0(0.0 \%)$ & $6(3.6 \%)$ & $0(0.0 \%)$ & $6(4.5 \%)$ & $0(0.0 \%)$ \\
\hline
\end{tabular}

*Biomedical courses include pharmacology, microbiology, biochemistry, anatomy, and physiology.

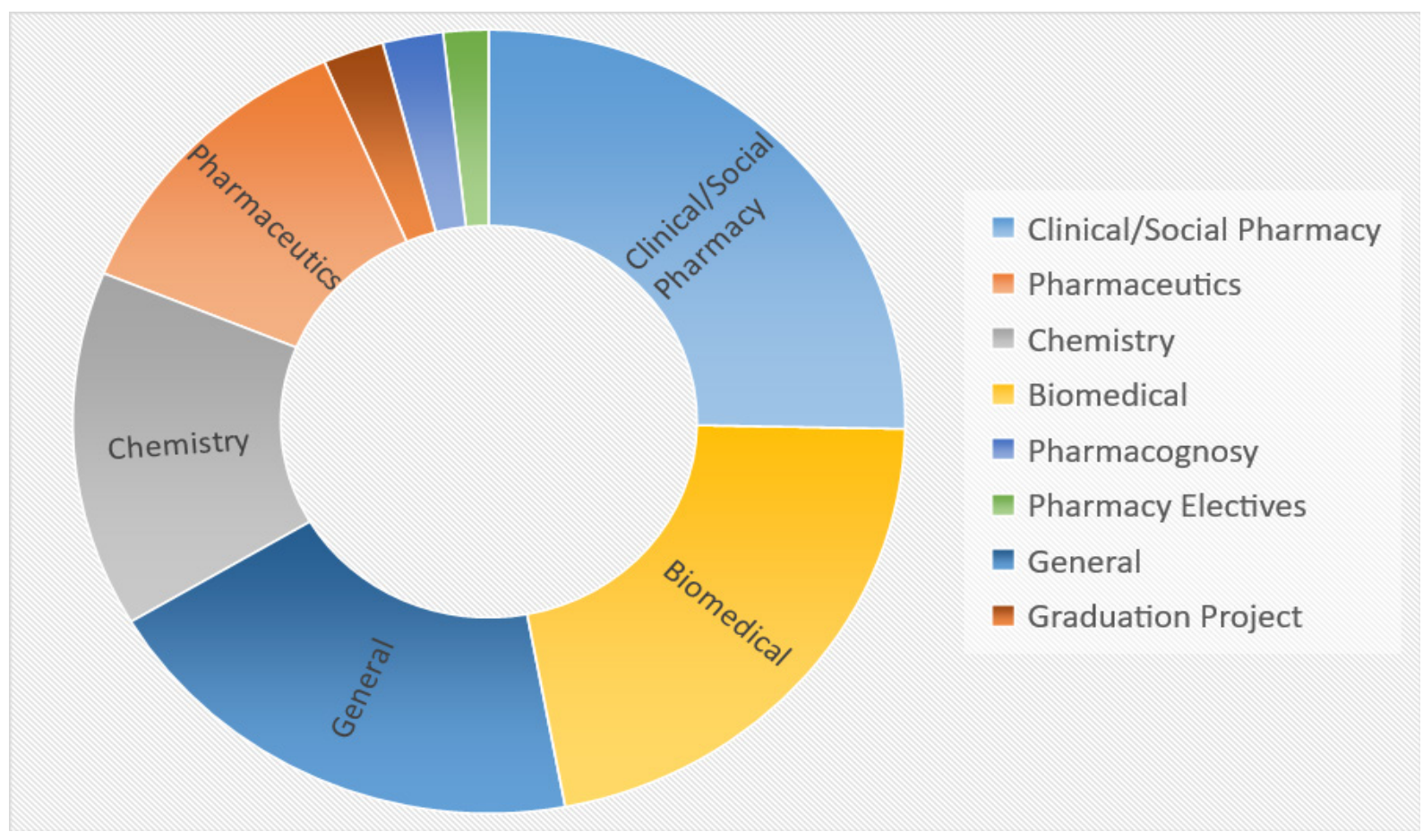

Figure 3. Course distribution of BPharm program courses in Ajman University 


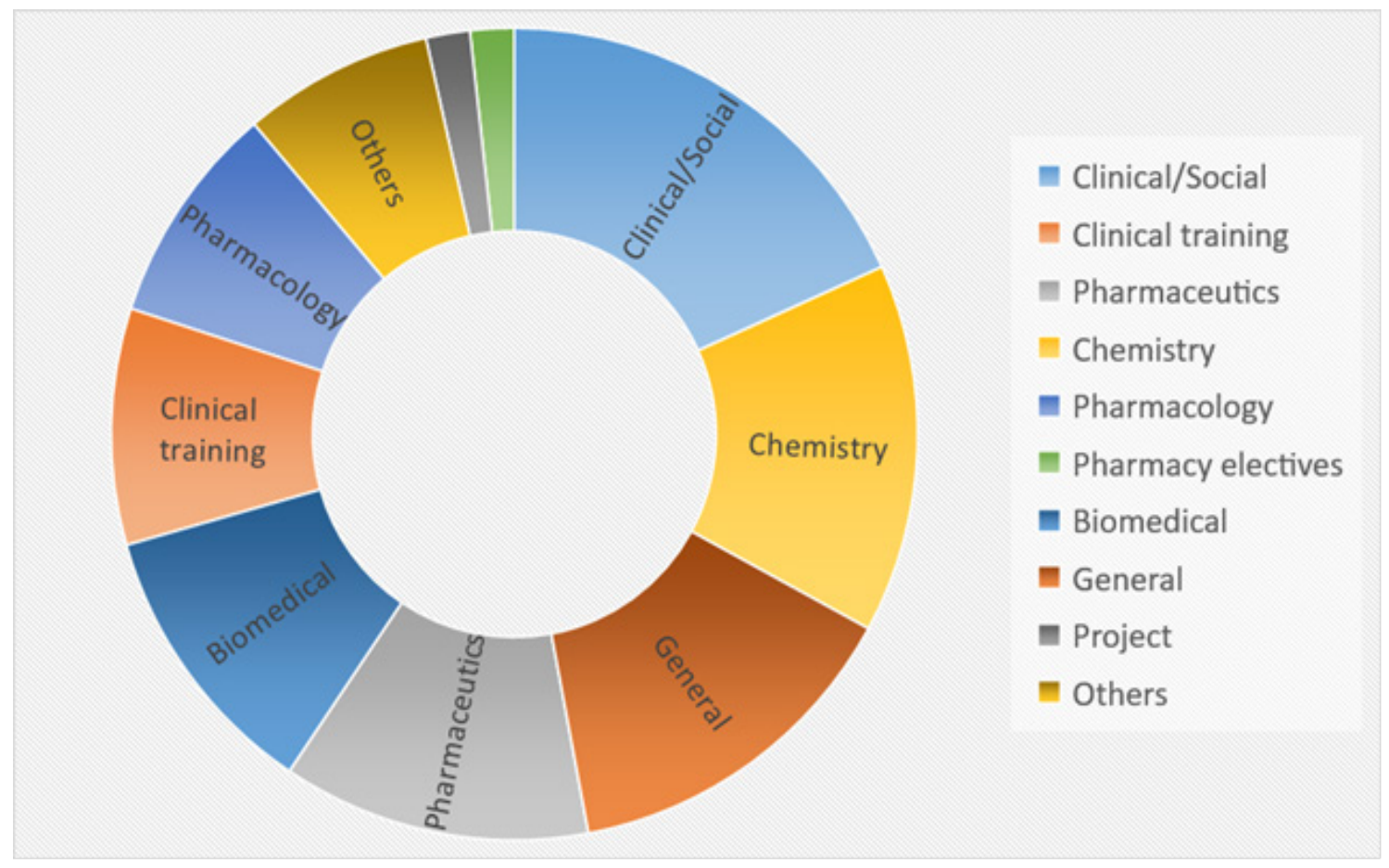

Figure 4. Course distribution of BPharm program courses in University of Sharjah

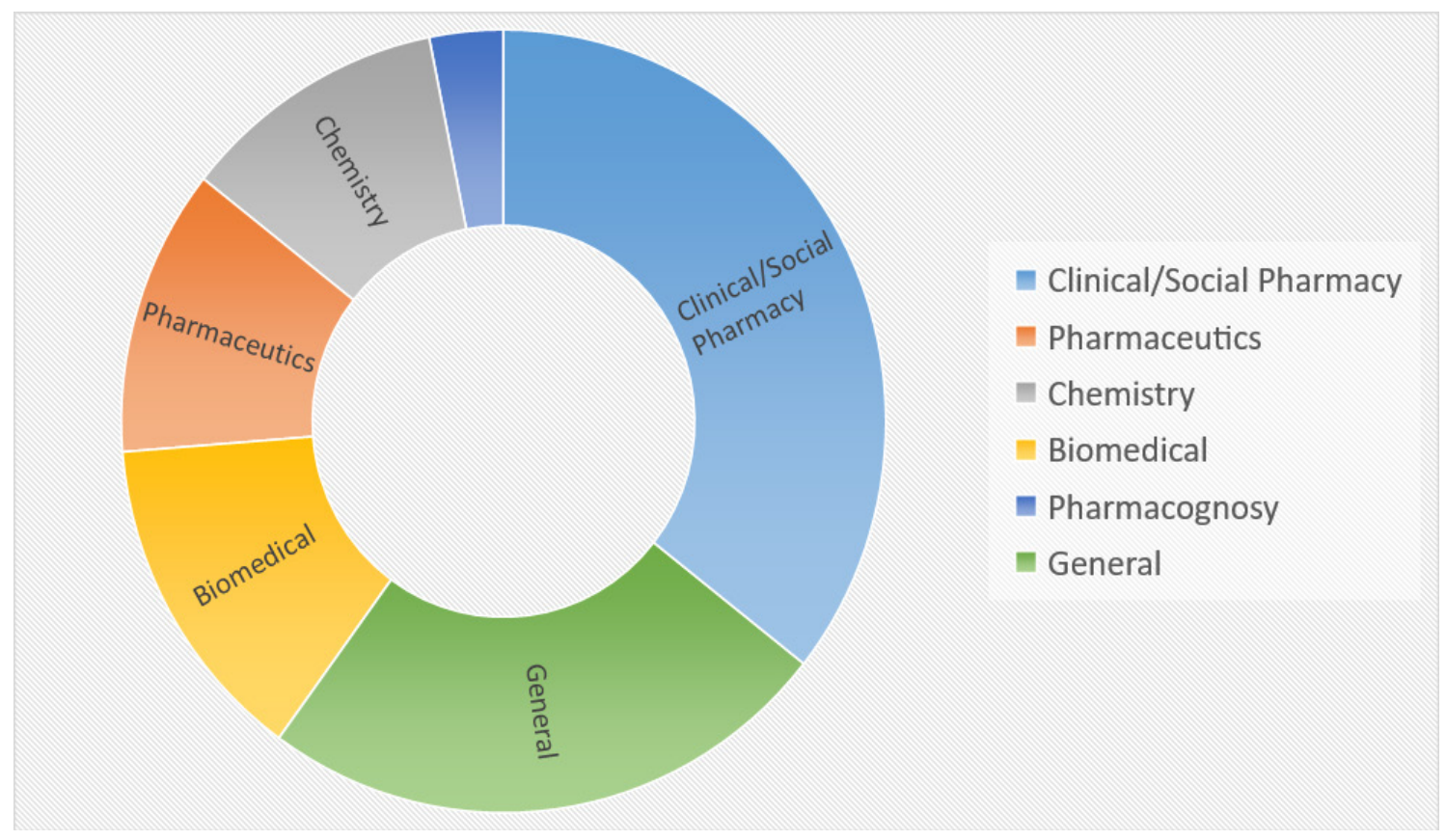

Figure 5. Course distribution of BPharm program courses in Al Ain University of Sciences and Technology 


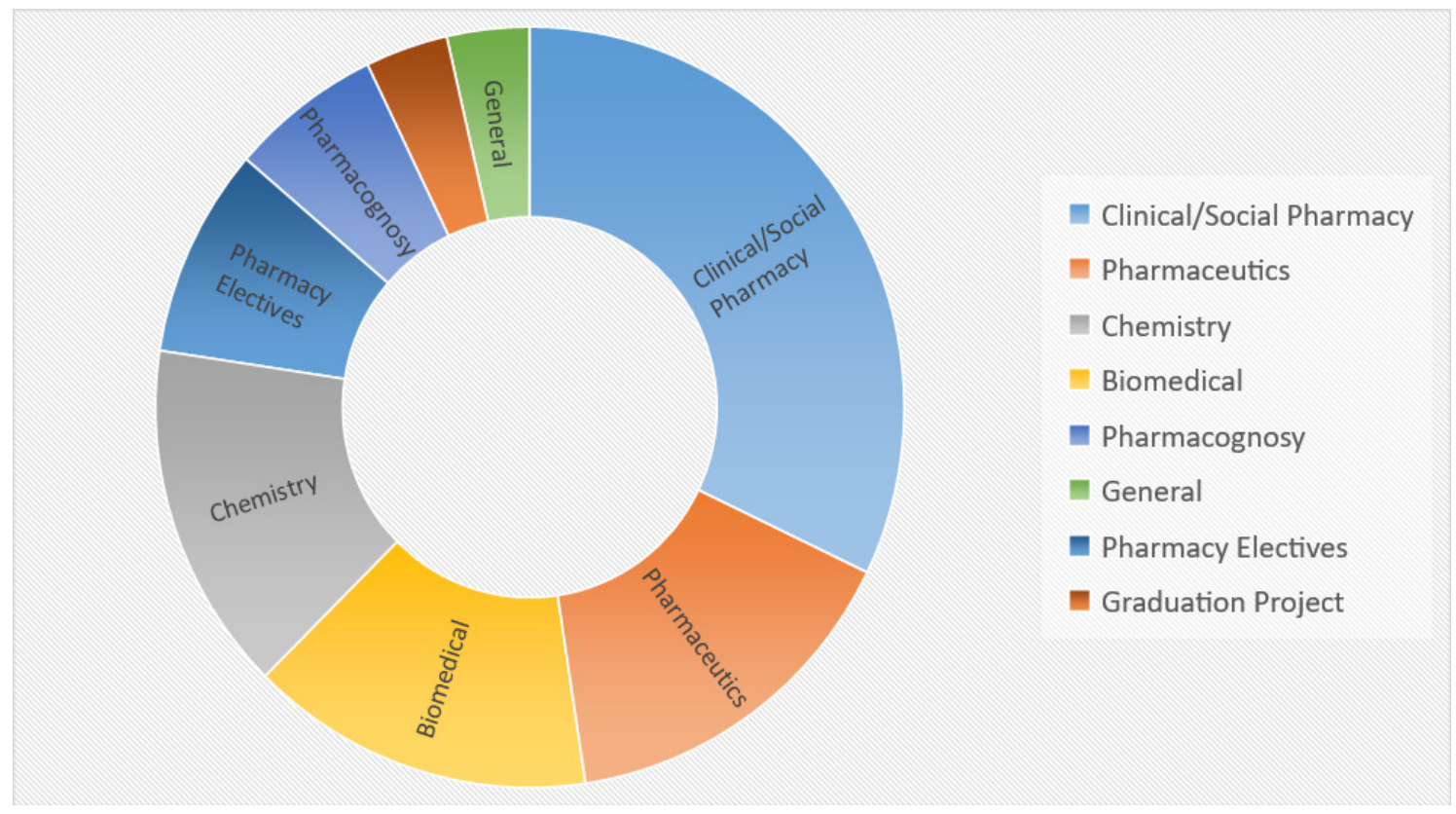

Figure 6. Course distribution of BPharm program courses in Dubai Pharmacy College

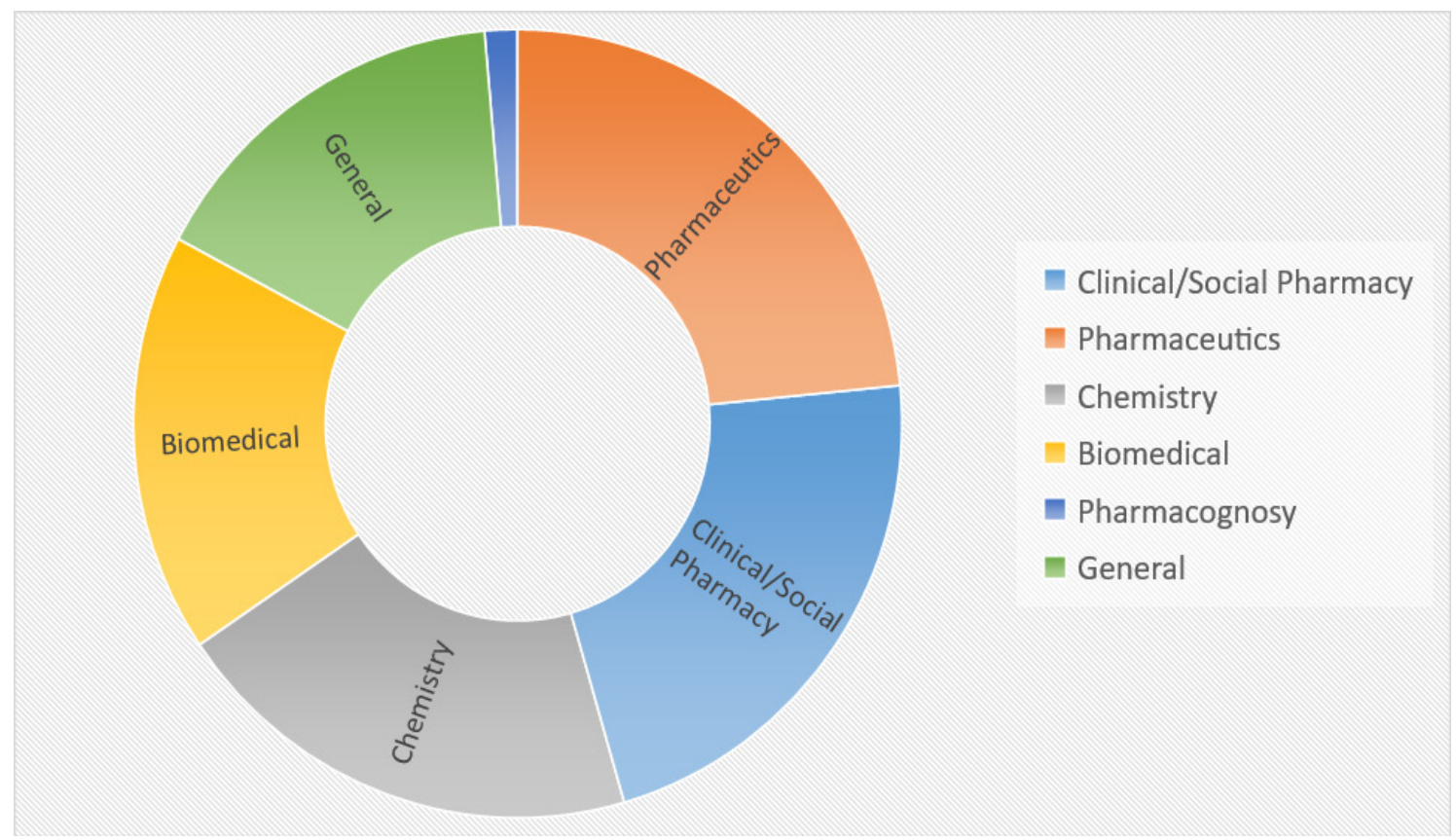

Figure 7. Course distribution of BPharm program courses in RAK Medical \& Health Sciences University 


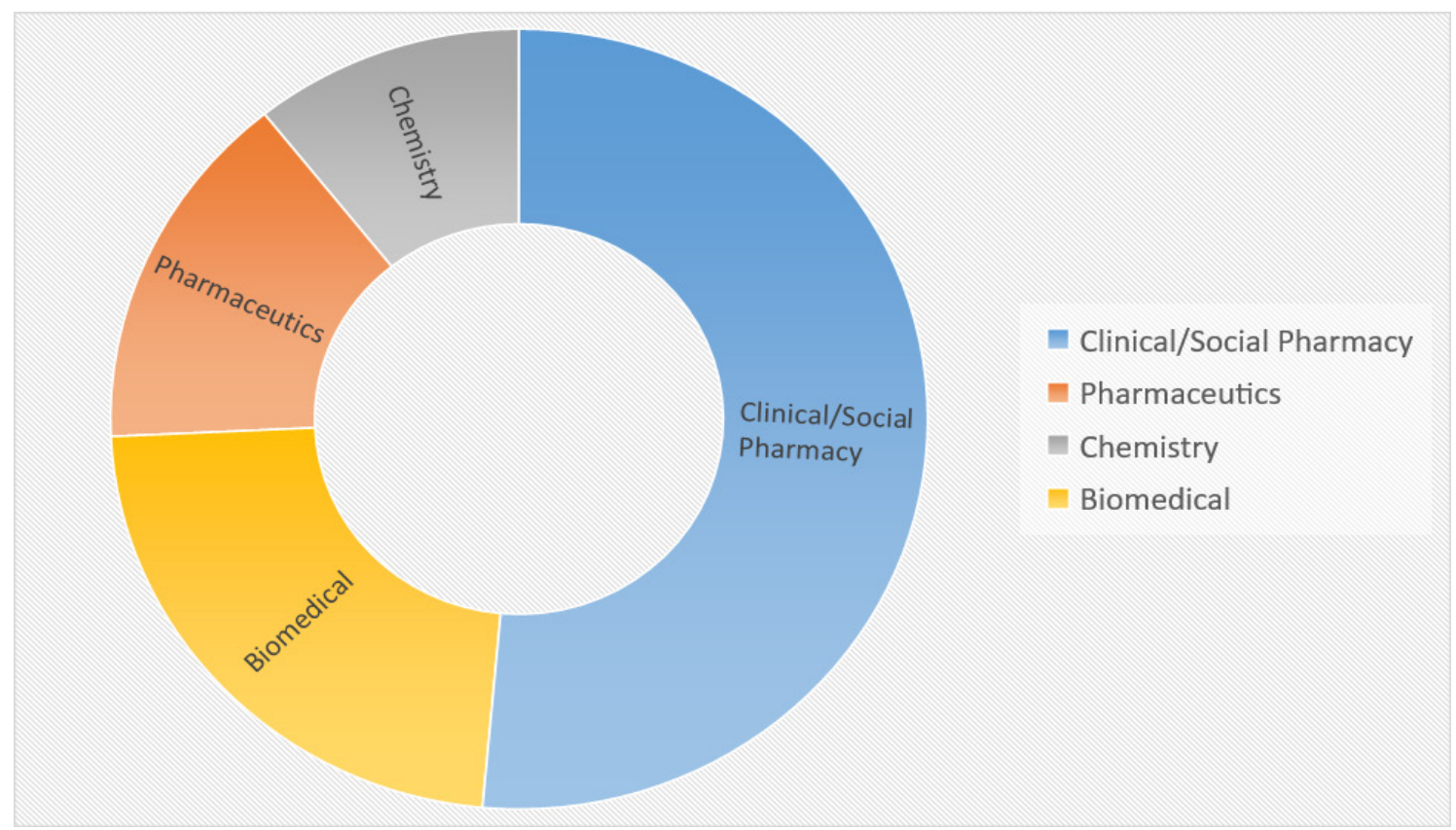

Figure 8. Course distribution of BPharm program courses in Dubai Women College, HCT

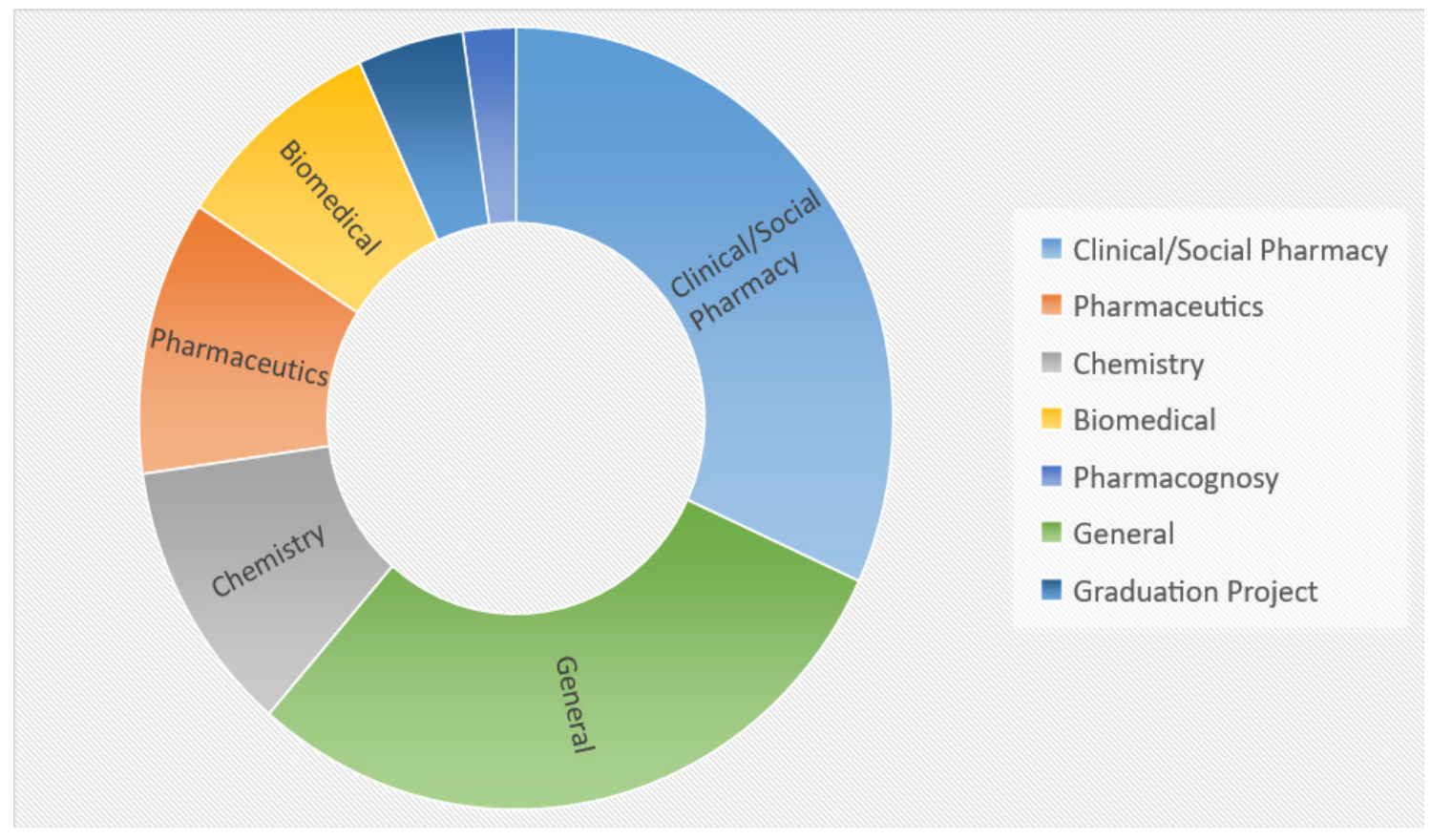

Figure 9. Course distribution of BPharm program courses in Fatima College of Health Sciences 


\section{Clinical/ Social Courses and Training}

A good number of credit hours of traditional courses in specialties such as pharmaceutics, chemistry, and biomedical sciences was replaced with courses related to patient care and counseling as well as some other courses dealing with pharmacoeconomics, management, marketing, pharmacovigilance, and pharmacogenomics. Clinical and social pharmacy courses represent between $22.1 \%$ (in RAK) to $51.4 \%$ (FCHS) of the total BPharm credit hours (Figure 10).

Clinical/ social pharmacy courses vary from one program to another (Table 5). Pharmacotherapy course is the only clinical course that is offered by all programs ranging from 7 to 33 credit hours. All the colleges, but FCHS, offer pharmacy law and ethics course. The number of credit hours allocated for clinical training/experiential experience varies from one program to another ranging from 9 to 16 credit hours.

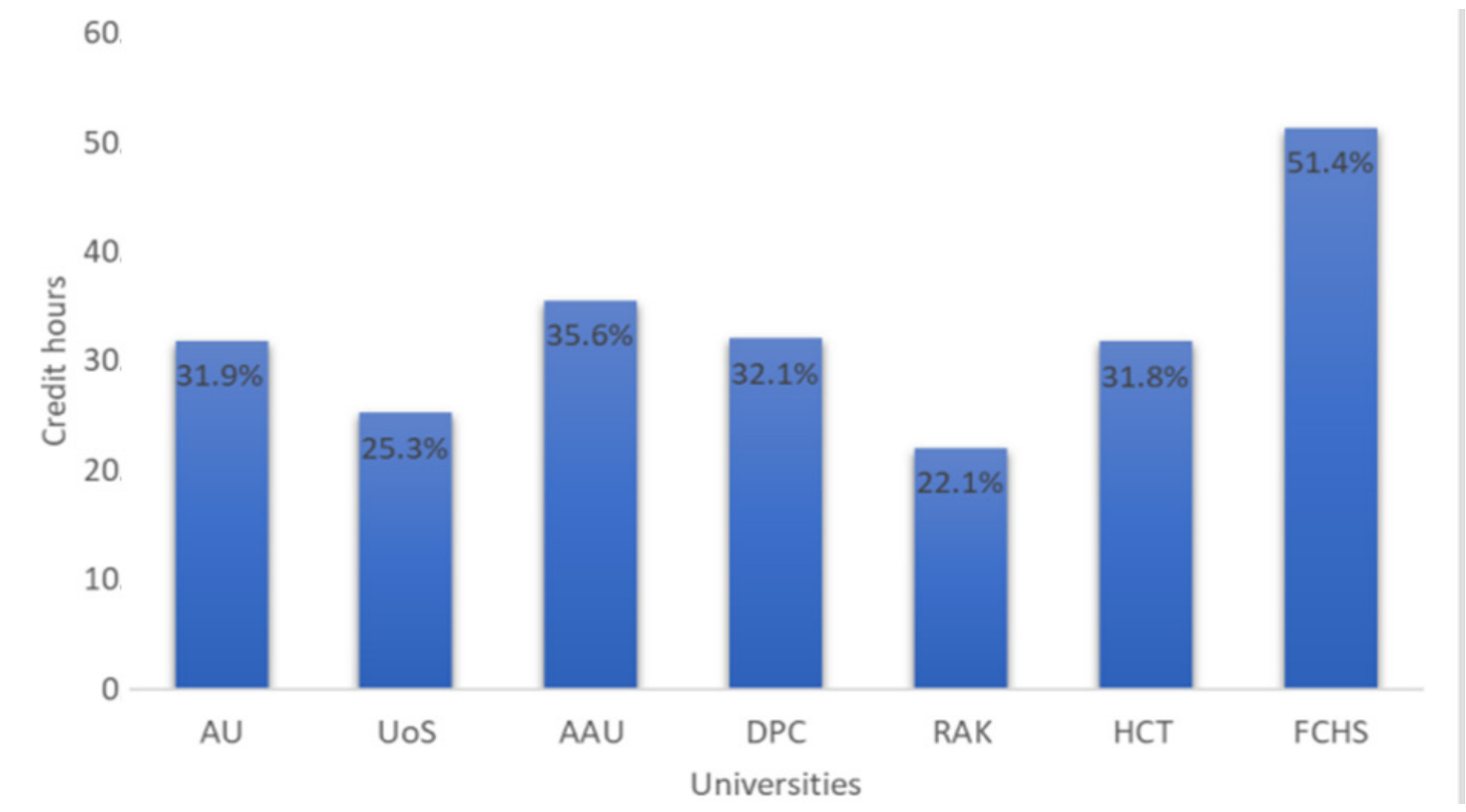

Figure 10. Number of credit hours of clinical/social pharmacy in BPharm programs offered by different pharmacy colleges in UAE

Table 5. Distribution of clinical/social courses in BPharm programs offered by pharmacy colleges in UAE

\begin{tabular}{|c|c|c|c|c|c|c|c|}
\hline Chemistry Course & AU & UoS & AAU & DPC & RAK & HCT & FCHS \\
\hline Pharmacotherapy (Therapeutics) & 9 & 12 & 11 & 7 & 12 & 9 & $33 *$ \\
\hline Non-prescription Drugs (OTC) & 4 & 3 & 4 & - & - & - & - \\
\hline Drug Information/Literature Evaluation & 3 & 3 & 3 & - & - & - & - \\
\hline Pharmacy Law and Ethics & 2 & 2 & 3 & 1 & 4 & 3 & - \\
\hline Management/Economics/Marketing & 4 & 2 & 3 & 2 & - & 3 & - \\
\hline Pharmaceutical Care & 3 & 3 & 4 & 3 & - & 3 & - \\
\hline Pharmacovigilance/Epidemiology & 2 & - & 3 & 3 & - & - & - \\
\hline Training & 16 & 16 & 9 & 12 & 10 & 15 & 14 \\
\hline Others & 8 & 12 & 20 & 24 & 8 & 9 & 25 \\
\hline Total & 51 & 43 & 57 & 54 & 32 & 42 & 72 \\
\hline BPharm Total Credit Hours & 160 & 170 & 160 & 168 & 145 & 132 & 140 \\
\hline Percentage & $31.9 \%$ & $25.3 \%$ & $35.6 \%$ & $32.1 \%$ & $22.1 \%$ & $31.8 \%$ & $51.4 \%$ \\
\hline
\end{tabular}

*Integrated courses 


\section{Non-Clinical/ Social Courses}

The increase in the number of clinical/social pharmacy courses of newly revised BPharm curricula offered by UAE universities has led to relatively decrease in the credit hours allocated for "non-clinical/social" courses. The "slow crawl" of clinical courses to replace traditional ones is a controversial topic. Some academicians attributes this trend to the needs of job market, whereas others see it as a negative impact on the role of pharmacists in many areas such as research and development, quality control and assurance, pharmaceutical industry, and natural products industry.

Historically, pharmaceutics courses used to dominate BPharm programs in most of UAE universities. The recent program developments have led to a remarkable decrease in the credit hours of many pharmaceutics courses such as pharmaceutical technology and pharmacokinetics and biopharmaceutics. Pharmaceutics courses represent range from $11 \%$ to $16 \%$ in most of BPharm curricula in UAE, except the RAK pharmacy college where the pharmaceutics courses still dominate the BPharm program with close to $24 \%$ of the program total credit hours (Figure $11)$.

Pharmacy-related chemistry courses were also affected by recent developments in BPharm curricula. Future pharmacists who are also known as chemists, especially in Commonwealth English countries, will be no longer taking the same number of credit hours previously devoted to traditional chemistry courses such as analytical chemistry and instrumental analysis, organic chemistry, and medicinal chemistry. The credit hours of chemistry courses in most BPharm programs in UAE range from $11 \%$ to $16 \%$, except in RAK where the percentage is close to $20 \%$ (Figure 12).

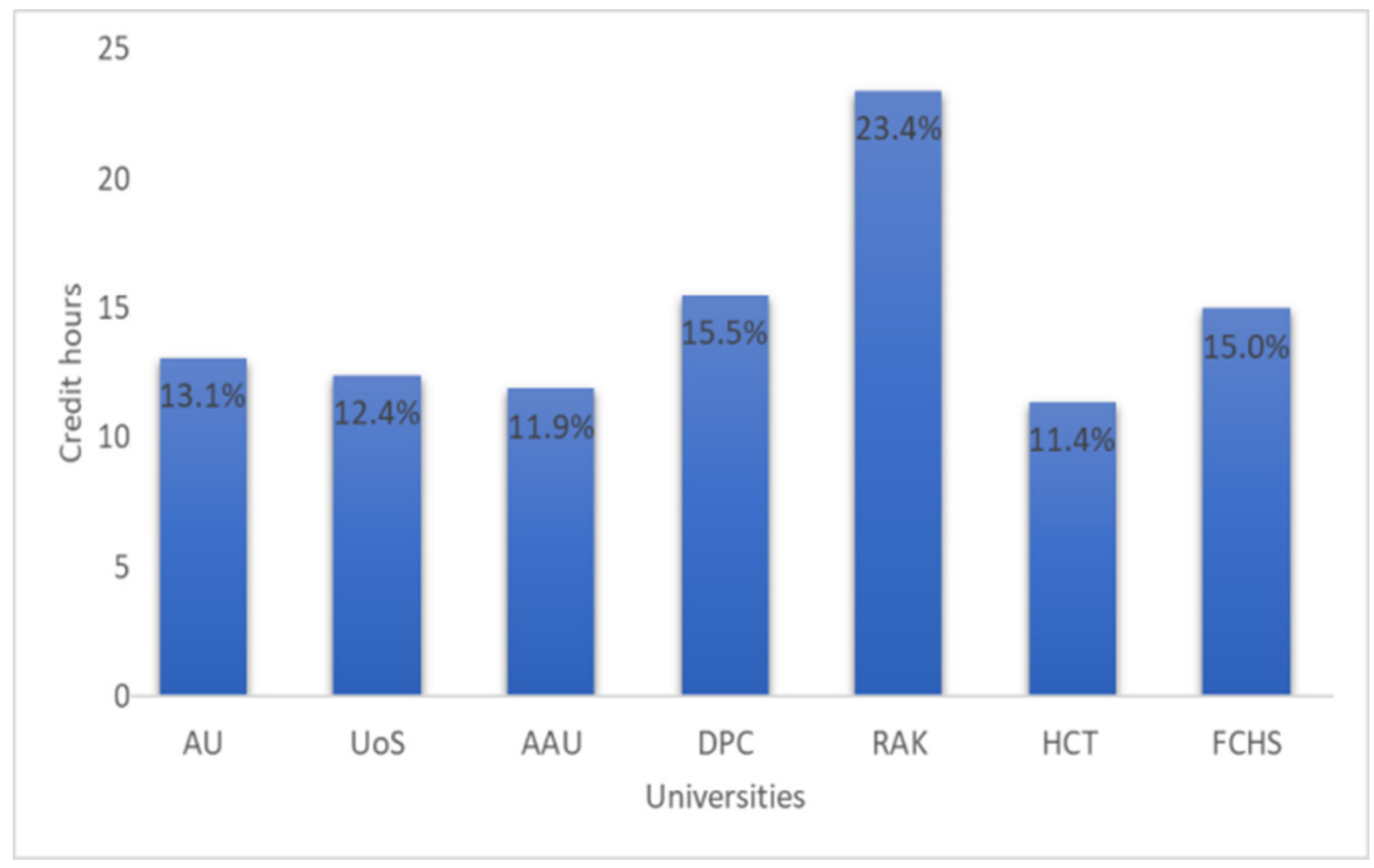

Figure 11. Number of credit hours of pharmaceutics courses in BPharm programs offered by different pharmacy colleges in UAE 


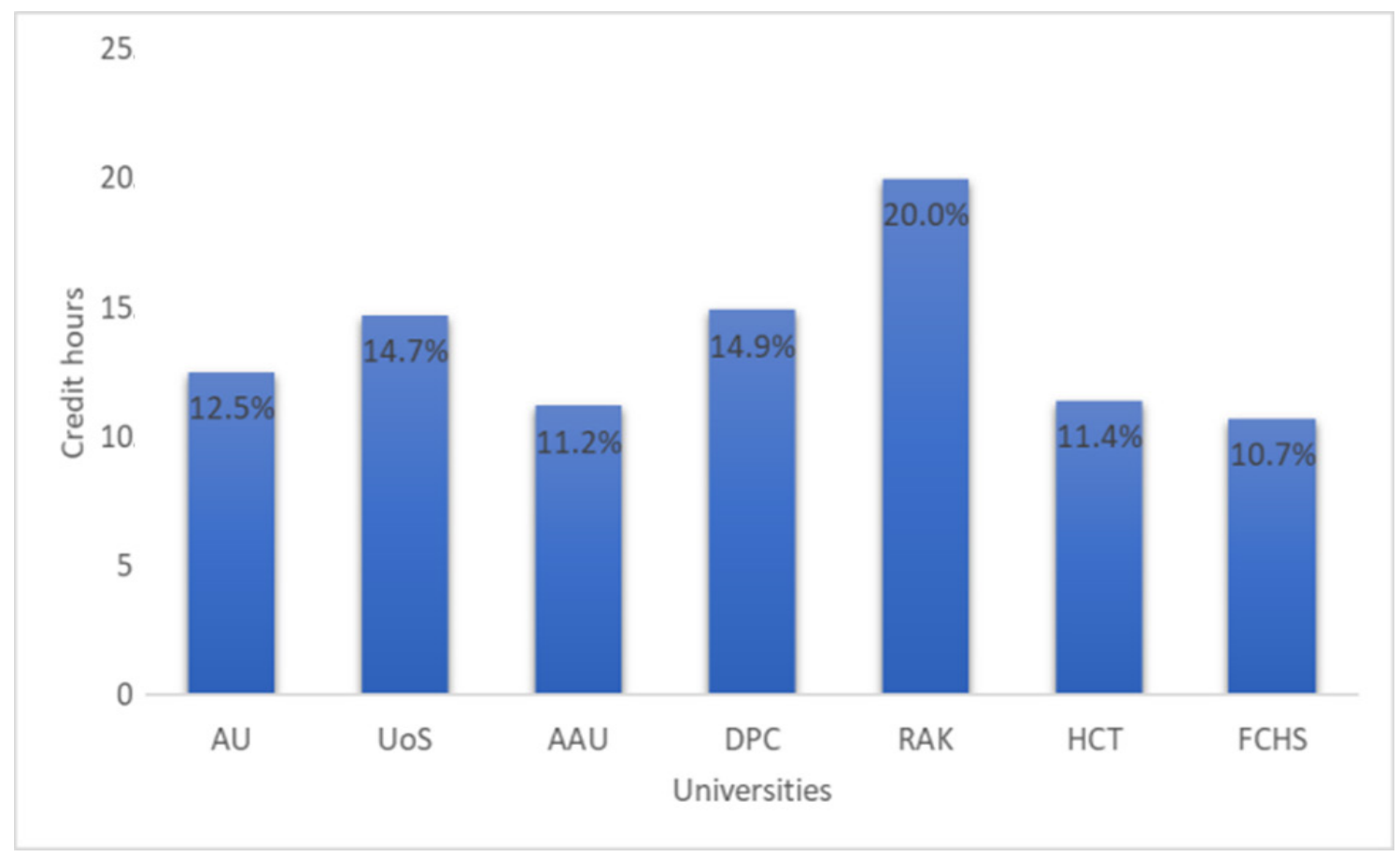

Figure 12. Number of credit hours of chemistry courses in BPharm programs offered by different pharmacy colleges in UAE

Table 6. Distribution of chemistry courses in BPharm programs offered by pharmacy colleges in UAE

\begin{tabular}{|c|c|c|c|c|c|c|c|}
\hline Chemistry Course & AU & UoS & AAU & DPC & RAK & HCT & FCHS \\
\hline General Chemistry & - & 4 & 3 & - & 3 & 3 & 5 \\
\hline Organic Chemistry & 6 & 9 & 5 & 7 & 6 & 3 & 5 \\
\hline Pharmaceutical Analysis & 6 & - & 4 & 7 & 12 & 3 & - \\
\hline Quality Control/Assurance & 3 & - & - & - & - & - & - \\
\hline Medicinal Chemistry & 5 & 12 & 6 & 11 & 5 & 6 & 5 \\
\hline Inorganic Chemistry & - & - & - & - & 3 & - & - \\
\hline Total & 20 & 25 & 18 & 25 & 29 & 15 & 15 \\
\hline BPharm total credit hours & 160 & 170 & 160 & 168 & 145 & 132 & 140 \\
\hline Percentage & $12.5 \%$ & $14.7 \%$ & $11.2 \%$ & $14.9 \%$ & $20.0 \%$ & $11.4 \%$ & $10.7 \%$ \\
\hline
\end{tabular}

Among the common six chemistry courses typically taught in BPharm programs, medicinal chemistry, pharmaceutical analysis (including analytical chemistry and instrumental analysis), and organic chemistry represent the most common chemistry courses that are present in most BPharm curricula, in contrast to quality control/assurance and inorganic chemistry courses that are only offered by two colleges (Table 6). Medicinal chemistry and organic chemistry are the only courses that are offered in all programs.

\section{PharmD Program}

To date, GMU is the only university that offers a PharmD as an undergraduate-level pharmacy program, and more PharmD programs may be offered in the future by other universities. Despite the growing interest of offering PharmD in UAE, this program may lack one of its most important components, which is the residency. One of the barriers of PharmD programs in many countries is the unavailability of residency positions in hospitals, including those in United States, to accommodate the demands of PharmD students. For this reason, PharmD programs without residency may not be equated with its counterpart in other countries such as United States. Additionally, PharmD holders should be distinguished from BPharm graduates in terms of job description and employee grade and position levels. BPharm and PharmD holders have the same definition in the professional qualifications requirements (PQR) document of the UAE health authorities, which sets the professional qualification requirements needed for licensing healthcare professionals in the UAE. 


\section{Integrated Curriculum}

Integrative teaching and learning in pharmacy has not been well implemented in the Middle East and North African (MENA) region. Many challenges and barriers may face the development and implementation of integrated BPharm curricula in UAE in particular and other MENA countries in general. First, the implementation requires increasing in the number of faculty members of different specialties of pharmacy. This is a challenging issue since almost all the pharmacy colleges in UAE are private, and hiring large number of faculty may not be a suitable direction from a financial standpoint. Second, since this pedagogical method is uncommon for students and faculty, resistance is likely to happen, especially if it lacks to incentives.

\section{Recent Developments}

The minimum total credit hours for BPharm programs in UAE and experiential education were among the main topics discussed in the Pharmacy Education Summit held in Ajman in March 2019, with the participation of UAE pharmacy colleges key figures and the Commission for Academic Accreditation (CAA) in UAE Ministry of Education, Accreditation Council of Pharmacy Education (ACPE) in USA and American Association of Colleges of Pharmacy (AACP). It was decided to set a minimum of 150 credit hours of BPharm programs and at least 960 contact experiential hours with 24 credit hours for training courses. It was also a discussion about the importance for BPharm programs in UAE to offer balanced blend of biomedical, pharmaceutical and clinical sciences, and that incorporating more social courses and experiential learning is important but without negatively affecting pharmaceutical sciences courses that are the backbone of pharmacy (20).

\section{Conclusions}

Pharmacy education in UAE has recently undergone drastic developments, and more clinical and social pharmacy courses are increasingly replacing the traditional pharmaceutical sciences subjects. Most of pharmacy colleges have developed their curricula toward patient centered pharmacy education. This has led to marked decrease in the number of credit hours dedicated for other courses such as pharmaceutics, chemistry, biomedical, and basic sciences. PharmD programs are not widespread in $\mathrm{UAE}$, however, there is a growing interest of offering this degree program by a number of UAE universities, but some regulatory affairs need to be adopted.

\section{Conflict of Interest}

The author declares no conflict of interest.

\section{Acknowledgements}

The author would like to thank all contributors from colleges of pharmacy in Ajman University, Al Ain University of Sciences and technology, and University of Sharjah for the information they supplied to support data published in this work.

\section{REFERENCES}

[1] Population and Demographic, Population Census 2017. Federal Competitiveness and Statistics Authority (FCSA); 2017 [cited 2019 Jan 13]. Available from: http://fcsa.gov.ae/en-us/Pages/Statistics/Statistics.aspx

[2] Population and Demographic, Population Census 2017. Federal Competitiveness and Statistics Authority (FCSA); 2017 [cited 2019 Jan 13]. Available from: http://fcsa.gov.ae/en-us/Pages/Statistics/Statistics.aspx

[3] Nunes-da-Cunha I, Arguello B, Martinez FM, Fernandez-Llimos F. A comparison of patient-centered care in pharmacy curricula in the United States and Europe. American journal of pharmaceutical education. 2016 Jun 25; 80(5):83.

[4] Dameh M. Pharmacy in the United Arab Emirates. South Med Rev. 2009; 2(1):15.

[5] Kheir N, Zaidan M, Younes H, El Hajj M, Wilbur K, Jewesson PJ. Pharmacy education and practice in 13 Middle Eastern countries. Am J Pharm Educ. 2008; 72(6):133.

[6] Fathelrahman AI, Rouse MJ. Quality and Accreditation in Pharmacy Education. In: Pharmacy Education in the Twenty First Century and Beyond. Elsevier; 2018. p. 21369.

[7] Alkhateeb FM, Arkle S, McDonough SL, Latif DA. Review of National and International Accreditation of Pharmacy Programs in the Gulf Cooperation Council Countries. Am J Pharm Educ. 2018; 82(10):5980.

[8] Hasan S, Sulieman H, Chapman C, Stewart K, Kong DC. Community pharmacy in the United Arab Emirates: characteristics and workforce issues. Int $\mathrm{J}$ Pharm Pract. 2011; 19(6):392-9.

[9] Sarheed O, Al-Azzawi AM, Nagavi BG. Pharmacy education in the United Arab Emirates. Am J Pharm Educ. 2014; 78(2):45.

[10] Population and Demographic, Higher Education 2017 [Internet]. Federal Competitiveness and Statistics Authority (FCSA); 2017 [cited 2019 Jan 13]. Available from: http://fcsa.gov.ae/en-us/Pages/Statistics/Statistics.aspx 
[11] Procedural Guidelines for Renewal of Accreditation. Commission for Academic Accreditation, Ministry of Education; 2011 [cited 2019 Jan 10]. Available from: https://www.caa.ae/caa/images/Guide-RA.pdf

[12] Accreditation Council for Pharmacy Education Directory of Programs with Certification Status. American Accreditation for Pharmacy Education (ACPE); [cited 2019 Jan 13]. Available from: https://www.acpe-accredit.org/pdf/ISP/Dir ectoryofCertifiedPrograms.pdf

[13] Ajman University. BPharm Study Plan, Ajman University. 2019 [cited 2019 Jan 14]. Available from: https://www.ajman.ac.ae/en/

[14] BPharm Program, University of Sharjah. University of Sharjah; [cited 2019 Jan 14]. Available from: http://www.sharjah.ac.ae/en/academics/Colleges/Pharmacy /Pages/Bachelor-of-Pharmacy.aspx

[15] BPharm Study Plan, Al Ain University of Sciences and Technology. Al Ain University of Sciences and Technology; [cited 2019 Jan 14]. Available from: https://pharmacy.aau. ac.ae/en/programs/pharmacy/study-plan/

[16] BPharm Study Plan, Dubai Pharmacy College. Dubai Pharmacy College; [cited 2019 Jan 14]. Available from: http://www.dpc.edu/academics.php?category_id=3

[17] RAK BPharm Study Plan. RAK Medical \& Health Science University; [cited 2019 Jan 14]. Available from: http://www.rakmhsu.com/pharmacy-college-in-dubai/study -plan/b-pharm/

[18] FCHS BPharm Study Plan. Institute of Applied Technology, Fatima College of Health Sciences (FCHS); [cited 2019 Jan 14]. Available from: http://www.fchs.ac.ae/En/Programs/P ages/Pharmacy.aspx

[19] BPharm Program, Dubai Women's College, HCT. Dubai Women's College, Higher Colleges of Technology; [cited 2019 Jan. Available from: http://www.hct.ac.ae/en/progra $\mathrm{mmes} / \mathrm{p} /$ health-sciences-in-pharmacy/

[20] College of Pharmacy News. Ajman University; Available from: https://www.ajman.ac.ae/en/pharmacy.html 